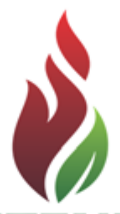

SUSTENERE

Publishing Corporation
ZRBADM

Journals Homepage:

www.sustenere.co/journals

\section{SISTEMAS AGROINDUSTRIAIS SUSTENTÁVEIS: UMA APLICAÇÃO DA ECONOMIA DOS CUSTOS DE TRANSAÇÃO}

\section{RESUMO}

Entender a coordenação de sistemas produtivos sustentáveis torna-se fundamental para a análise da própria competitividade e eficiência do agronegócio. Sendo as atividades do agronegócio fortemente dependentes da utilização dos recursos naturais, o tema agronegócio e sustentabilidade são claramente relacionados. $\mathrm{O}$ presente artigo objetiva descrever e compreender o padrão da governança e o papel das instituições e das organizações para a coordenação do sistema de produção e comercialização de hortaliças orgânicas do projeto PAIS (Produção Agroecológica Integrada e Sustentável) em Campo Grande/MS. O projeto PAIS e uma iniciativa do SEBRAE Nacional que tem como foco a geração de renda para agricultores familiares, aliando práticas sustentáveis às atividades produtivas. Como arcabouço teórico utiliza-se a Nova Economia Institucional (NEI), especificamente, a Economia dos Custos de Transação (ECT). A pesquisa é de natureza exploratória e adota uma abordagem qualitativa com levantamento de dados primários por meio da aplicação de questionários semiestruturados junto a 37 produtores. Foram identificadas e caracterizadas as transações existentes ao logo do sistema produtivo, além da avaliação do perfil das famílias de produtores envolvidas no projeto. Verificou-se que o sistema projeto PAIS se subdivide em dois subsistemas, sendo um com atuação de uma cooperativa e outro sem ações associativas. Destaca-se como ponto principal do projeto a garantia de venda da produção aos programas governamentais, que têm grande relevância para o escoamento da produção. Da mesma forma, a alta dependência dos programas governamentais e a heterogeneidade dos produtores representam vulnerabilidades do sistema produtivo.

PALAVRAS-CHAVES: Agronegócio; Sustentabilidade; Economia dos Custos de Transação; Coordenação.

\section{SUSTAINABLE AGRO INDUSTRIAL SYSTEMS: AN ECONOMY OF THE APPLICATION OF TRANSACTION COSTS}

\begin{abstract}
The understanding of the coordination of sustainable agribusiness systems is essential for the analysis of own competiveness and agribusiness efficiency. Once agribusiness activities are strongly dependent on natural resources, agribusiness and sustainability theme are clearly related. The present article aims to describe and comprehend the governance standard and the institutions and organizations roles for coordinating the productive and marketing systems of organics vegetable trade of the Integrated and Sustainable Agroecological Production (ISAP) in Campo Grande/MS. The ISAP Project is an initiative of National SEBRAE which focuses on generating income for family farmers, combining sustainable practices with productive activities. The theoretical framework rested on New Institutional Economics (NIE), specifically on Transaction Costs Economics (TCE). This research is exploratory and it adopts a qualitative methodological approach with primary data mapping, using semi-structured questionnaires with 37 farmers. The transactions were identified and characterized along the productive system, beyond the evaluation of the farmers' families profile involved in the project. It was verified that ISAP Project is divided in two subsystems, one with a cooperative actions and other without them. The guarantee production sale to government programs stands out as the main point of the Project, which have been relevant to the production flow. Likewise, the high reliance on governmental programs and the heterogeneity of producers represent vulnerabilities of the productive system itself.
\end{abstract}

KEYWORDS: Agribusiness; Sustainability; Transaction Costs Economics; Coordination.
Revista Brasileira de

Administração Científica,

Aquidabã, v.5, n.3, Jul, Ago, Set,

Out, Nov, Dez 2014.

ISSN 2179-684X

SECTION: Articles

TOPIC: Gestão Ambiental

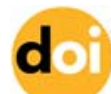

DOI: 10.6008/SPC2179-684X.2014.003.0017

Devanildo Braz da Silva

Universidade Federal de Mato Grosso do Sul, Brasil http://lattes.cnpq.br/4624810056908982 devabraz@ibest.com.br

Silvia Morales de Queiroz Caleman Universidade Federal de Mato Grosso do Sul, Brasil http://lattes.cnpq.br/0777852000128223 silvia.caleman@ufms.br

Received: 29/07/2014

Approved: 17/08/2014

Reviewed anonymously in the process of blind peer.

Referencing this:

SILVA, D. B.; CALEMAN, S. M. Q.. Sistemas agroindustriais sustentáveis: uma aplicação da economia dos custos de transação. Revista Brasileira de Administração Científica, Aquidabã, v.5, n.3, p.287304, 2014. DOl: http://dx.doi.orq/10.6008/SPC2179$684 X .2014 .003 .0017$ 


\section{INTRODUÇÃO}

O agronegócio se caracteriza pela construção e coordenação de relações sistêmicas entre os elos de uma cadeia produtiva. Compreender a complexidade das relações econômicas desenvolvidas no âmbito do agronegócio é fundamental para se traçar estratégias públicas e privadas, pois cada vez mais a busca pela eficiência é a força motriz que rege a organização de sistemas produtivos. As organizações têm voltado suas forças para identificar o arranjo que proporcione maior competitividade, não somente internamente, mas para além das suas fronteiras, de forma a tornarem-se competitivas pela eficiência nas transações que executam com fornecedores, parceiros e clientes, assim como com as organizações de apoio.

Atualmente, o tema da sustentabilidade tem grande importância para as organizações e também para toda a sociedade, haja vista a crescente conscientização da necessidade de melhoria nas condições ambientais, econômicas e sociais, de forma a aumentar qualidade de vida de toda a sociedade. Sendo as atividades do agronegócio fortemente dependentes da utilização dos recursos naturais, o tema agronegócio e sustentabilidade são claramente relacionados. Também, a sustentabilidade surge como um fator que pode agregar maior competitividade ao agronegócio, sobretudo em termos de diferenciação do produto, de estratégias de entrada em novos mercados ou mesmo como forma de atendimento de uma demanda específica no mercado em que a organização atua.

Com isso, questões que envolvam a coordenação de sistemas produtivos sustentáveis tornam-se fundamentais para a análise da própria competitividade e eficiência do agronegócio. Ou seja, a questão chave é a promoção e a garantia de práticas sustentáveis ao longo dos sistemas agroindustriais. Em outras palavras, sustentabilidade e coordenação são dimensões importantes para a gestão do agronegócio contemporâneo. Considerando a importância da coordenação para a promoção da competitividade, aliada ao aspecto sistêmico da análise dos Sistemas Agroindustriais (SAGs), entende-se que o estudo da sustentabilidade na produção agropecuária deve ir além das questões técnicas de produção, incorporando, também, o estudo das relações entre os agentes econômicos. Assim, a promoção da sustentabilidade em sistemas produtivos agropecuários implica a minimização dos custos de transação, para o que entender o padrão da relação entre os agentes econômicos ao longo de cadeias produtivas sustentáveis é fundamental.

Nesse sentido, ganha força o papel das instituições e das organizações de apoio como agentes de apoio à coordenação de SAGs. North (1991) diz que as instituições são as regras que regem as estruturas políticas, econômicas e de interação social, podendo ser informais (sanções, tabus, costumes, tradições e códigos de conduta) ou formais (constituições, leis, direito de propriedade). Nota-se que a eficiência econômica está fortemente aliada à boa atuação por parte das instituições envolvidas no processo, tanto formal como informalmente.

Uma iniciativa que busca a produção agrícola sustentável é o projeto Produção Agroecológica Integrada e Sustentável (PAIS), que tem como foco a geração de renda para 
agricultores familiares, por meio da produção integrada e ambientalmente sustentável. O projeto PAIS é uma iniciativa do SEBRAE Nacional (Serviço Nacional de Apoio às Micro e Pequenas Empresas), financiada pela Fundação Banco do Brasil e apoiada pelo Governo Federal, através do Ministério da Integração Nacional e do Ministério do Desenvolvimento Social. As prefeituras aderem ao projeto, nos locais em que é implementado, por meio de convênios, ficando responsáveis pela seleção dos participantes e pela assistência técnica, contando para isso com o apoio do SEBRAE local. Os objetivos principais do projeto são: geração de renda para agricultores familiares (tradicionais, assentados e quilombolas) e a produção de alimentos sustentáveis.

Em se tratando do projeto PAIS em Campo Grande/MS, objeto de estudo desta pesquisa, tem-se a produção de hortaliças orgânicas por agricultores familiares. Entende-se que este projeto engloba variáveis importantes para a análise de uma iniciativa de coordenação de sistemas agroindustriais sustentáveis, em especial a organização de pequenos produtores rurais, sendo parte deles atuando por meio de uma cooperativa, a produção orgânica, regulamentada por legislação específica e a importante atuação de organizações de apoio e fomento.

Com base nos pressupostos da Nova Economia Institucional (NEI), em específico, as variáveis de análise propostas pela Economia dos Custos de Transação (ECT), o presente artigo tem como objetivo descrever e compreender o padrão da governança e o papel das instituições e organizações para a coordenação do sistema de produção e comercialização de hortaliças orgânicas do projeto PAIS em Campo Grande/MS. Especificamente, busca-se: mapear o SAG e identificar o padrão das transações existentes; descrever o padrão de governança adotado pelos agentes econômicos e entender o papel das instituições e organizações para o desempenho desse sistema produtivo.

\section{REVISÃO TEÓRICA}

\section{Nova Economia Institucional}

A Nova Economia Institucional (NEI) desenvolveu-se na vertente de análise da competitividade sob duas correntes, com características complementares, o Ambiente Institucional, com foco na análise de macro-instituições, e Instituições de Governança, que analisa as micro-instituições. Ambas tratam num nível analítico distinto o mesmo objeto: a economia dos custos de transação. Ambas correntes recorrem a conceitos comuns, como custos de transação, instituições e organizações (AZEVEDO, 1997).

O enfoque da NEI está no ambiente institucional e na governança. Por ambiente institucional entendem-se as regras do jogo, formais e informais, e os direitos de propriedade, cujo propósito é obter o ambiente institucional mais adequado. Já por governança, entende-se o alinhamento das estruturas de governança com as transações, cujo propósito é obter a estrutura de governança mais adequada, eliminando custos de transação (WILLIAMSON, 2000). 
Azevedo (1997, p.55) diz que custos de transação são os "custos que são necessários para se colocar o mecanismo econômico e social em funcionamento". Em outras palavras, são os custos que não estão diretamente ligados à produção, mas que surgem no relacionamento entre os agentes e os problemas de coordenação que emergem. Para Williamson (1996), custos de transação são os custos anteriores ('ex ante') e posteriores ('ex-post') a um contrato, representados pelas preparações e negociações, assim como pelas adaptações e ajustes necessários para corrigir imperfeições ocorridas na execução da transação.

De açodo com North (1991) instituições são limitações construídas pelos seres humanos, que estruturam a interação social, econômica e política. Elas consistem em restrições informais (sanções, tabus, costumes, tradições e códigos de conduta) e regras formais (constituições, leis e direitos de propriedade). Ao longo da história, as instituições foram criadas por seres humanos para criar ordem e reduzir a incerteza nas trocas. De acordo com Azevedo (1997), a corrente de ambiente institucional dedica-se ao estudo das regras do jogo, enquanto que a corrente de instituições de governança estuda as transações sob um enfoque micro analítico. Destaca o autor que para melhor desenvolvimento da $\mathrm{NEI}$, é preciso um tratamento mais unificando, explorando as interrelações entre as duas principais correntes, sob um instrumental comum. Zylbersztajn (1995) destaca que as grandes mudanças nas instituições são menos frequentes a curto prazo, tendendo a ocorrerem mudanças incrementais a longo prazo, de cunho cultural, costumes e o aparato legal.

\section{Economia dos Custos de Transação}

A Economia dos Custos de Transação (ECT) é um ramo da NEl que sustenta que a transação é a unidade básica da análise das trocas econômicas. Os estudos da ECT colocam a problemática das organizações como um problema de contratação. Com isso, os contratos têm grande importância e a definição da melhor forma contratual fará com que haja redução dos custos de transação (WILLIAMSON, 1985). O objetivo fundamental da ECT 'é o de estudar o custo das transações como o modo indutor dos modos alternativos de organização da produção (governança), dentro de um arcabouço analítico institucional' (ZYLBERSZTAJN, 1995). Complementa o autor que a unidade de análise fundamental passa ser a transação.

Ao se analisar um SAG, observa-se que o processo envolvido desde o fornecimento dos insumos até a chegada do produto ao consumidor final é feito por uma série de transações entre os agentes envolvidos. North (2006) diz que todas as operações de um sistema econômico estão sujeitas aos custos de transação.

\section{Pressupostos Comportamentais e Atributos da Transação}

São dois os pressupostos comportamentais que são necessários à compreensão da ECT: a racionalidade limitada e o oportunismo (ZYLBERSZTAJN, 1995). Esses dois pressupostos 
dizem respeito, respectivamente, à limitação dos agentes na tomada de decisão da transação e à possibilidade de alguma das partes buscar obter vantagem de forma aética sobre a outra. Entendê-los é fundamental para o desenho do arranjo necessário para coordenar as transações. O conceito de racionalidade limitada está alicerçado na ideia de que os indivíduos agem racionalmente, mas de modo limitado. Isso devido ao fato de que nem todas as informações necessárias à tomada de decisão são acessíveis ou mensuráveis, devido à complexidade ou ao custo envolvido (AZEVEDO, 1997).

Para Williamson (1985) o oportunismo pode ser entendido como a busca pelos interesses próprios, com astúcia, o que inclui mentir, roubar e enganar, mas frequentemente ocorre com formas mais sutis. Complementa o autor que geralmente, o oportunismo refere-se a divulgação incompleta ou distorcida de informações, especialmente com os esforços calculados para enganar, distorcer, disfarçar, ofuscar ou de outra forma confundir. Em tese, a falta de previsão contratual, em algum item acordado entre as partes ou que seria intrínseco à transação, não seria nenhum problema, mas com essa possibilidade, há o incentivo para o comportamento oportunista. Assim, verifica-se que a informação assimétrica pode ser responsável, por sérios problemas de desempenho contratual (FURUBOTN \& RICHTER, 2000).

A ECT considera que existem razões econômicas racionais para organizar o modo das transações (WILLIAMSON, 1985). Cada transação tem suas particularidades, ou seja, transações diferem uma das outras quanto aos seus atributos. 'Esse é o motivo fundamental para explicar a existência de diferentes estruturas de governança para reger cada transação, como mercado spot, contratos ou integração vertical' (AZEVEDO, 1997). De acordo com Williamson (1985), as principais diferenças entre as transações ocorrem devido à especificidade dos ativos, a incerteza e a frequência. Podem ser considerados ativos específicos aqueles que não são facilmente reempregáveis em outras atividades ou transações, a não ser com perda de valor (AZEVEDO, 1997; ZYLBERSZTAJN, 2005).

De acordo com Williamson (1985), "pelo menos quatro diferentes tipos de especificidade de ativos é útil distinguir: a especificidade local; especificidade de ativos físicos; especificidade de ativos humanos e ativos dedicados". Além das especificidades citadas, tem-se a especificidade de marca e a especificidade temporal. A especificidade temporal pode ser relacionada à especificidade local, uma vez que a capacidade de agilidade no local dos ativos é vital para o sucesso da transação (WILLIAMSON, 1991). A frequência de uma transação está associada ao número de repetições de uma mesma espécie de transação e tem importância para determinar questões como diluição dos custos complexos em várias transações e possibilidade de construção de uma reputação entre os agentes envolvidos (AZEVEDO, 1997).

A frequência das transações impacta na redução de custos e possibilita a construção de reputação entre os agentes, diminuindo as incertezas que são características das transações. Além disso, a construção de reputação entre os agentes diminui a possibilidade de comportamento oportunístico, pois estabelece confiança entre as partes (CALEMAN, 2005). A 
incerteza é uma condição em que não se pode determinar a probabilidade de um evento ocorrer, não sendo possível definir uma forma segura de prevenção a eventuais riscos advindos do evento (NORTH, 1991).

\section{Estruturas de Governança}

As estruturas ou formas de governança são classificadas em mercado, formas híbridas e hierarquia. Cada uma dessas se diferencia da outra nos aspectos contratuais. Além disso, há diferenças significativas na adaptabilidade e na utilização de instrumentos de incentivo e controle (WILLIAMSON, 1996). No mercado, as transações são realizadas em um único instante, sendo tipicamente esporádico, além de alto grau de incerteza, sobretudo por falta de frequência nas transações. Nos contratos, buscam-se a estabilidade da relação e o comprometimento futuro com a transação, sendo definidos os termos acordados entre as partes, além das garantias. $\mathrm{Na}$ integração, as transações são feitas internamente à empresa, sendo esta estratégia utilizada quando os custos são menores que os demais mecanismos de comercialização (AZEVEDO, 2009).

De acordo com Zylbersztajn (2005), a escolha da estrutura de governança mais eficiente depende do tipo de especificidade de ativos, onde os ativos com alta especificidade exigem maiores cuidados com as salvaguardas contratuais, pois as perdas tendem a ser elevadas em caso de ruptura contratual por uma das partes. Ménard (2004) destaca que os contratos são incompletos e sujeitos à imprevisibilidade, uma vez que são sobre transações que envolvem ativos específicos e que estão frequentemente em ambiente de incertezas.

Nos casos de alta especificidade de ativos, onde o monitoramento é mais intenso, é apropriada a estrutura hierárquica. No outro extremo, onde as transações são caracterizadas por ativos pouco específicos, em que os agentes não sofrerão perdas no caso de ruptura dos contratos, as relações com outros agentes ocorrem via mercado, sendo as transações regidas pelo sistema de preços, não importando a questão da reputação do agente. Já nos casos intermediários, que são os mais comuns, estão as formas de governança mista ou contratual, também chamada de formas híbridas, onde o desenho dos contratos tem grande importância para a eficiência das transações (ZYLBERSZTAJN, 2005).

De acordo com Azevedo (2009), a coordenação é construída pelos integrantes dos sistemas produtivos, com a finalidade de reduzir custos de transação, utilizando-se de mecanismos de comercialização apropriados para efetuar uma determinada transação.

\section{METODOLOGIA}

A presente pesquisa pode ser definida como exploratória, quanto aos fins e pesquisa de campo, quanto aos meios. De acordo com Vergara (2009), quanto aos meios uma pesquisa pode 
classificada como de campo, de laboratório, documental, bibliográfica, experimental, ex post facto, participante, pesquisa-ação ou estudo de caso. A pesquisa exploratória é uma pesquisa realizada em área na qual há pouco conhecimento acumulado e sistematizado. Já uma pesquisa descritiva expõe características de determinada população ou de determinado fenômeno e pode também estabelecer correlações entre variáveis e definir sua natureza (VERGARA, 2009).

Para a realização da pesquisa foram aplicados questionários semiestruturados, por meio de entrevista pessoal do pesquisador com os entrevistados, junto aos agentes econômicos (produtores rurais) que compõem o sistema pesquisado e também com as organizações de apoio. A população da pesquisa foi composta por 115 produtores de hortaliças orgânicas no município de Campo Grande, integrantes do projeto Produção Agroecológica Integrada e Sustentável (PAIS). A amostragem da presente pesquisa foi não probabilística.

O presente estudo se utilizou da amostragem por julgamento, onde, pelo quantitativo reduzido da população e distância geográfica, em princípio, todos os elementos da população interessavam ao estudo. Para tanto, o pesquisador esteve em todas as localidades indicadas, para aplicar os questionários pessoalmente aos produtores. Entretanto, no decorrer da pesquisa foram excluídos da população inicial os produtores rurais que desistiram do projeto. Assim, efetivamente obteve-se uma população de 48 elementos/produtores, sendo pesquisados 37 deles.

Somente foram consideradas desativadas as unidades em que houve confirmação de abandono do projeto feita pelo proprietário e/ou líder comunitário. O quantitativo de unidades consideradas ativas foi estabelecido a partir das unidades em que foi efetuada a pesquisa, aquelas em que o responsável se encontrava ausente e aquelas em que não foi possível confirmar se houve abandono do projeto.

As transações analisadas foram as que envolvem diretamente os produtores, quais sejam: Insumos - Produtor (T1); Produtor - Atacado (T2); Produtor - Varejo (T3); Produtor - Consumidor final (T4); e Produtor - Programas governamentais (T5). Para o desenvolvimento da pesquisa, o questionário abordou, além de questões para caracterização geral, questões com as variáveis de análise: racionalidade limitada; incompletude dos contratos; oportunismo; frequência; incerteza; especificidade de ativos; coordenação; estruturas de governança; e instituições e organizações.

\section{O Projeto Pais e o SAG De Hortaliças Orgânicas}

A Tecnologia Social PAIS foi idealizada em 1999, na região de Petrópolis/RJ, pelo engenheiro agrônomo Aly Ndiaye. O objetivo foi criar uma alternativa de trabalho e renda para os agricultores familiares, produzindo alimentos mais saudáveis, tanto para o consumo próprio quanto para a comercialização, utilizando-se de técnicas simples já conhecidas pelos produtores rurais sem o uso de produtos tóxicos e com a preocupação de preservação do meio ambiente (SEBRAE, 2009). 
De acordo com o SEBRAE (2009), a tecnologia social do PAIS é agroecológica porque dispensa o uso de ações danosas ao meio ambiente, como o emprego de agrotóxicos (adubo e veneno), queimadas e desmatamentos; é integrada porque alia a criação de animais com a produção vegetal e ainda utiliza insumos da propriedade em todo o processo produtivo; e é sustentável porque preserva a qualidade do solo e das fontes de água, incentiva o associativismo dos produtores e aponta novos canais de comercialização dos produtos, permitindo boas colheitas agora e no futuro.

Um dos passos da implantação e desenvolvimento do projeto PAIS é o associativismo e a comercialização. Com isso, os agricultores devem criar canais de distribuição dos seus produtos por meio de convênios com prefeituras, órgãos públicos e com o comércio local. Devem organizarse em entidades, como associações e cooperativas, de forma a facilitar a participação nos programas governamentais. Nesse sentido, faz parte do programa a capacitação em cultura associativa, empreendedorismo e acesso a mercados locais e regionais (SEBRAE, 2009).

A partir de 2005, o PAIS foi implementado nacionalmente pelo SEBRAE, com o apoio da Fundação Banco do Brasil e em parceria com o Ministério da Integração Nacional e Ministério do Desenvolvimento Social, (SEBRAE, 2009). Em 2010 o projeto contava com 2.700 unidades instaladas, em 15 estados (RO, MT, MS, GO, MG, ES, BA, SE, AL, PB, RN, CE, PI, PA e PE), abrangendo 53 municípios (FERNANDES, 2011).

No Projeto PAIS de Campo Grande têm-se 115 produtores de todas as regiões do município. Parte dos produtores integra a Cooperativa dos Produtores de Orgânicos da Agricultura Familiar de Campo Grande (Organocoop), os quais têm sua produção certificada pelo Instituto Biodinâmico (IBD). Parte da produção dos cooperados é comercializada em duas feiras viabilizadas pela prefeitura e administradas pela cooperativa; outra parte é destinada a programas governamentais, que visam melhorar a renda de agricultores familiares, venda direta no local da produção e/ou venda no atacado. Entre os programas governamentais, têm-se o Programa de Aquisição de Alimentos (PAA) e o Programa Nacional de Alimentação Escolar (PNAE). Para os não cooperados, a única diferença nos canais de comercialização é a não utilização das feiras.

Os cento e quinze produtores de Campo Grande que iniciaram no projeto PAIS são de diversas regiões da cidade, desde a área urbana, até assentamentos rurais localizados a $120 \mathrm{~km}$ da região central, passando por distritos e outros assentamentos com distâncias menores. Neste município o projeto iniciou-se em dezembro de 2008. Em setembro de 2009 foi instalada a primeira feira destinada à venda dos produtos orgânicos e em agosto de 2010 foi criada a segunda feira. Em setembro de 2010 foi criada a Organocoop, com 58 cooperados, os quais estavam em processo de certificação de produção de produtos orgânicos. A certificação inicial ocorreu no mês de abril de 2011, com 63 produtores, sendo a maior parte cooperada, após o SEBRAE/MS contratar o IBD, que procedeu a avaliação das propriedades. Desde meados de 2012, a cooperativa conta com 85 cooperados, fruto do ingresso de outros agricultores familiares. 
O SAG das hortaliças orgânicas pode ser considerado um subsistema do SAG das hortaliças, dado suas particularidades e características próprias, tais como possuir organizações de apoio específicas e um ambiente institucional próprio, regido pela Lei $n^{\circ}$ 10.831/2003 e regulamentações, visto que um produto para ser considerado orgânico deve atender uma série de requisitos, o que está regulamentado na legislação citada. No caso do Projeto PAIS em Campo Grande/MS, entende-se que o mesmo subsistema apresenta ainda dois outros níveis: o subsistema das hortaliças orgânicas do projeto PAIS em que há uma cooperativa como agente coordenador (subsistema 1) e o subsistema das hortaliças orgânicas em que não há uma cooperativa como agente coordenador (subsistema 2).

Destaca-se que as organizações de apoio são as mesmas para ambos os subsistemas, com exceção das cooperativas, somente presentes no subsistema 2. Todas as outras organizações atendem tanto cooperados quanto não cooperados. O subsistema com cooperativa (subsistema 2), além dos benefícios comuns aos integrantes do projeto, viabilizadas pelos parceiros, apresenta alternativas para a comercialização da produção, como é o caso das feiras de produtos orgânicos. As feiras, no caso, são organizadas e gerenciadas pela cooperativa, tendo como feirantes unicamente os cooperados. Além disso, os produtores contam com a cooperativa como um agente de coordenação, que trabalha em prol dos cooperados, buscando as parcerias necessárias para desenvolver o projeto. Na figura 1, as setas com linhas cheias representam transações com troca de produtos, enquanto as setas com linhas tracejadas representam transações de troca de serviço entre produtor e cooperativa. Embora se configurem dois subsistemas, um para os produtores cooperados e outro para os não cooperados, não se percebe diferenças nas transações de comercialização efetuadas pelos produtores. Somente a feira de orgânicos (consumidor final) é um canal de distribuição exclusivo dos produtores cooperados.

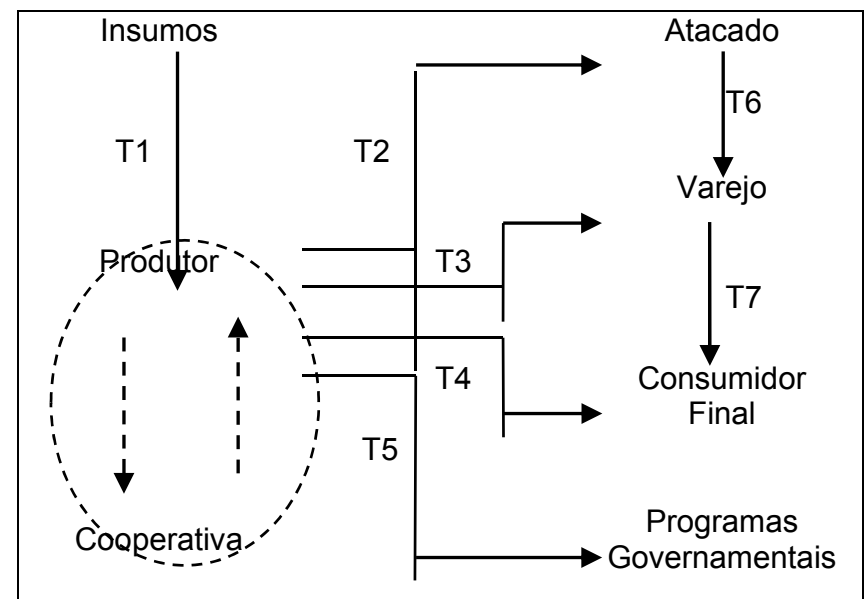

Figura 1: Sistema Agroindustrial do projeto PAIS em Campo Grande (MT).

\section{RESULTADOS}

\section{Caracterização dos Produtores e das Transações}


O total de cooperados entre os produtores pesquisados é de $73 \%$. Dos cooperados, $41 \%$ vendem entre 61 e $100 \%$ da sua produção por meio da cooperativa enquanto que $40 \%$ dos produtores cooperados vendem até $20 \%$ da produção por intermédio da cooperativa, conforme se observa na tabela 1.

Tabela 1: Venda por meio da cooperativa

\begin{tabular}{l|l}
\hline Faixa & Número de produtores \\
\hline Até $20 \%$ & 11 \\
\hline De 21 a $40 \%$ & 4 \\
\hline De 41 a $60 \%$ & 1 \\
\hline De 61 a $80 \%$ & 1 \\
\hline Entre 81 e $100 \%$ & 10 \\
\hline
\end{tabular}

Constata-se que um número razoável de produtores não utiliza ou utiliza pouco a cooperativa. Isso ocorre, principalmente, porque muitos dos produtores vendem diretamente para o PAA, não necessitando da interveniência da cooperativa. Além disso, mesmo a cooperativa tendo um caminhão à sua disposição, esse benefício não chega a todos os cooperados, sendo que boa parte deles utiliza veículo próprio ou paga frete para a entrega de seus produtos.

Dentre os produtores pesquisados, $78 \%$ afirmaram que $100 \%$ da sua produção de hortaliças é orgânica, sendo que $84 \%$ são certificados pelo Instituto Biodinâmico (IBD), que foi contratado pelo SEBRAE/MS, com recursos do projeto, tendo os produtores arcado com $10 \%$ do valor da certificação. As informações sobre a adoção de sistemas de produção orgânica e certificação são relevantes, pois permitem analisar a especificidade dos ativos envolvidos. Neste caso, a produção orgânica é entendida como de alta especificidade, sobretudo pelo processo produtivo, assim como pela certificação (REZENDE \& FARINA, 2001).

Para o custeio da produção, $97 \%$ dos entrevistados afirmaram que somente utilizam recursos próprios. Já em relação à assistência técnica, $78 \%$ informaram que recebe da prefeitura, $11 \%$ do SEBRAE/MS, 9\% da Agência de Desenvolvimento Agrário e Extensão Rural de Mato Grosso do Sul (Agraer) e 2\% alegam não receber assistência técnica. Embora a Agraer não seja parceira do projeto no município de Campo Grande (é parceira em outros municípios do estado), ela é citada porque desenvolve outros projetos em algumas das localidades pesquisadas, sendo que os produtores do PAIS são beneficiados direta ou indiretamente.

As transações do produtor com os fornecedores de insumos estão fortemente calcadas na aquisição à vista. Ainda, a maioria dos respondentes informou que utiliza recursos próprios para o custeio. Constata-se, também, que em alguns casos, os insumos básicos são produzidos pelos próprios produtores, o que certamente auxilia na redução de custos de produção. Pode-se, assim, afirmar que as transações para aquisição de insumos (T1) caracterizam-se como uma relação de mercado spot, com baixa especificidade.

Para a comercialização de seus produtos, é ampla a vantagem dos programas governamentais (PAA e PNAE) enquanto canais de distribuição para os produtores. Isso ocorre, principalmente, porque esses programas têm a garantia da compra da produção, respeitando os 
itens previamente acordados e os valores máximos anuais. Também a feira de orgânicos tem destaque como ponto de venda devido a sua regularidade e pontos fixos, sendo realizadas todas as quartas-feiras e sábados, na Praça do Rádio Clube e no estacionamento do Paço Municipal, respectivamente, sendo ambas as localidades na região central.

O PAA, principal ponto de venda, é uma das ações do Programa Fome Zero e promove o acesso a alimentos às populações em situação de insegurança alimentar, bem como promove o fortalecimento da agricultura familiar. A aquisição é feita isenta de licitação, com preços praticados no mercado regional. É desenvolvido pelo Ministério do Desenvolvimento Social e Combate à Fome (MDS) e pelo Ministério do Desenvolvimento Agrário (MDA). É implementado em cinco modalidades (compra direta, compra direta local com doação simultânea, formação de estoque, PAA leite e compra com doação simultânea), em parceria com a Companhia Nacional de Abastecimento (CONAB) e por governos estaduais e municipais (MDS, 2011).

Nesse sentido, cumpre destacar que no município de Campo Grande/MS são dois os PAAs existentes; sendo um administrado pelo município e outro pela CONAB. Os produtores podem fornecer para ambos, individualmente ou por meio da cooperativa, sendo necessária a aprovação da proposta.

As propostas, um tipo de projeto, são apresentadas pelos produtores interessados ou por uma cooperativa/associação aos gestores do PAA - município ou CONAB - para um período de um ano, contendo os itens que se dispõem a fornecer. Basicamente, o requisito para aprovação da proposta é a comprovação da condição de agricultor familiar. Após a aprovação, o produtor pode efetuar a entrega nos locais especificados, em dias da semana pré-estabelecidos, mas sem uma periodicidade definida. Assim, a única limitação é a cota anual, podendo o produtor entregar os itens/produtos com a frequência que melhor atender suas necessidades e/ou na medida em que efetuar as colheitas que destinará ao Programa.

\section{Padrão da Transação e das Estruturas de Governança}

Como formas de contratação prevalecem mecanismos formais. As vendas em feiras, no local da produção e/ou 'de porta em porta', são feitas a vista. A maior parte das vendas são para o programa governamental PAA, e se tem são projetos/propostas, que após aprovados habilitam os produtores à venda, onde são especificados os produtos a serem vendidos, mas sem um prazo definido, podendo ser no período de um ano, com uma limitação do programa, que é de quatro mil e quinhentos reais por projeto/proposta. Atendendo aos itens e com o limite financeiro, os produtores podem entregar de uma só vez ou parceladamente. Foi verificado que a maioria dos produtores entrega quinzenalmente ou mensalmente. Quanto ao PNAE, as entregas atendem ordem de compra, após os produtores participarem dos processos de compra, que são realizados diretamente pelas escolas ou centros de educação infantil. 
Em relação aos aspectos relacionados à negociação, os produtores demonstram ter um bom nível de conhecimento das informações necessárias ao fecharem os contratos, minimizando a incompletude dos contratos. A maior variabilidade nas respostas foi observada no questionamento sobre a "ter como garantir $100 \%$ a entrega da sua produção", onde $35 \%$ dos respondentes afirmaram que não têm como garantir. Essa negativa se dá, principalmente, pelas variações climáticas, que foi citado ser o maior problema da imprevisibilidade. Por outro lado, os produtores pesquisados apresentam confiam no comprador de seus produtos quanto à garantia de pagamento. Em relação à frequência das transações predominam as transações semanais, conforme se observa na tabela 2. De modo geral, a frequência das transações é alta, o que era esperado, visto se tratar de comercialização de produtos de alta perecibilidade.

Tabela 2: Frequência das transações.

\begin{tabular}{|c|c|c|c|c|}
\hline \multirow{2}{*}{ Local } & \multicolumn{4}{|c|}{ Percentual por Periodicidade } \\
\hline & Semanal & Quinzenal & Mensal & Esporádica \\
\hline Feiras ou local da produção & $89 \%$ & - & -- & $11 \%$ \\
\hline Mercados e supermercados & $33 \%$ & -- & -- & $67 \%$ \\
\hline Programas governamentais & $24 \%$ & $30 \%$ & $46 \%$ & -- \\
\hline De porta em porta & $67 \%$ & $11 \%$ & $22 \%$ & -- \\
\hline
\end{tabular}

Assim, existe regularidade na oferta de hortaliças por parte dos produtores, sendo a frequência das transações em sua maioria semanal, nas feiras ou no local da produção. Quanto às vendas nos locais da produção, essas ocorrem principalmente para a população do entorno, o que é compreensível, principalmente pela possibilidade do consumidor adquirir um produto recémcolhido. Os produtores informam que nessas vendas não tem um 'preço-prêmio' para o produto orgânico. Em relação à frequência das transações com os programas governamentais, embora não se tenha uma larga vantagem, as vendas quinzenais ou mensais são predominantes. Ocorre desta forma porque os produtores tendem a organizar sua produção para entregar entre 1 e 2 vezes no mês, gerando a maior parte da sua receita mensal.

Quanto à incerteza na comercialização dos produtos - recebimento dos valores acordados - a maioria dos entrevistados a classifica como baixa. Isso se dá principalmente porque a maior parte das vendas é para os programas governamentais, onde existe garantia de recebimento. Além disso, parte das vendas é efetuada à vista. Em relação aos prazos previstos para recebimento, $70 \%$ dos entrevistados relatam que sempre são respeitados, $27 \%$ relatam que às vezes são respeitados e $3 \%$ não responderam. Assim como o recebimento dos valores serem garantidos nos programas governamentais, o prazo para o recebimento é conhecido e normalmente é respeitado.

A baixa incerteza quanto ao recebimento e demais condições contratuais ocorrem porque a maior parte das vendas é para os programas governamentais, onde há garantia de recebimento, geralmente no prazo estipulado. Considerando o comportamento oportunista, $92 \%$ dos produtores entrevistados respondem negativamente ao questionamento "Já houve descumprimento de contrato/acordo por sua parte?". O mesmo percentual também responde negativamente ao questionamento relativo ao comprador. Como motivo para descumprir um contrato/acordo, os 
produtores que disseram já ter ocorrido, dizem que foi por perda da produção ocasionada por instabilidades climáticas. Em relação ao descumprimento por parte do comprador, os produtores relataram que ocorreu atraso no pagamento ou mesmo falta de pagamento.

Com isso, constata-se que o comportamento oportunista dos agentes não é uma restrição nesta transação. Entretanto, esta constatação é relativa, devido ao fato de que a maior parte das transações comerciais é realizada com os programas governamentais, onde há uma garantia de pagamento, mas não se tem um compromisso de entrega por parte dos produtores, nem risco de descredenciamento em caso de rompimentos. Nos casos em que poderiam ensejar contratos e sua quebra, de uma ou outra parte, as poucas transações que ocorrem são vendas à vista, ou seja, governadas pelo mercado.

A especificidade da transação entre produtores de hortaliças orgânicas do projeto PAIS e clientes (Governo, consumidores finais, atacadistas e varejistas) foi avaliada com base na especificidade locacional, especificidade física, especificidade temporal, especificidade humana e especificidade de marca. A distância do local de produção até os locais de comercialização é bastante variada, mas com maior concentração de localidades que têm entre 21 e $60 \mathrm{~km}$ de distância máxima até o local da venda ou entrega.

Questionados se seria possível transferir sua produção para outra localidade, sem perda de qualidade e sem aumentar custos, 95\% dos entrevistados respondeu que não é possível. Como justificativa, afirmam que além do custo da terra, teriam o custo de preparo do solo e, em alguns casos, colocação de sistemas de irrigação, assim como reiniciar o processo de conversão no modo de produção da terra, de convencional para orgânico. Com base nestas duas variáveis distância do local de produção e possibilidade de transferência de área - entende-se que a especificidade locacional é alta.

Em relação à utilização de equipamentos específicos para a produção de hortaliças, $73 \%$ dos entrevistados relatam que não tem qualquer equipamento, enquanto que $27 \%$ relatam ter algum equipamento. Entre os produtores que têm equipamentos, os equipamentos informados são microtrator e/ou bomba de pulverização que não caracterizam alta especificidade. No entanto, o ativo "terra" deve ser considerado como específico para a produção de hortaliças orgânicas, pois tem um preparo diferenciado das demais culturas e exige um tempo para sua conversão para a produção de orgânicos. Assim, entende-se que a especificidade física é média na transação em análise.

Quanto ao armazenamento da produção, $78 \%$ dos entrevistados relatam não ser possível. Os $22 \%$ que relatam poder armazenar, informam que é possível o armazenamento apenas de abóbora madura ou ainda em câmara fria, por um período de até 7 dias. A dificuldade de armazenamento, aliada à alta perecibilidade do produto, conferem alta especificidade temporal à transação. Todos os produtores entrevistados informaram que seus produtos não têm marca. Nesse sentido, alguns relataram que a cooperativa está preparando um local para pré- 
processamento, com fracionamento e embalagem. Quando entrar em operação, deverá ter a identificação da cooperativa nas embalagens.

Assim, com essas informações, é possível afirmar que não existe especificidade de marca e que é alta a especificidade temporal. Também, a especificidade de ativos físicos existe, mas é baixa, assim como é alta especificidade local. Além disso, existe a especificidade do ativo humano, pois o produtor precisa conhecer os procedimentos para a produção e comercialização das hortaliças orgânicas.

Do total que relata produzir orgânicos, $69 \%$ informam que consegue receber um preço prêmio devido ao produto ser orgânico, sendo este bônus da ordem de $30 \%$. Outros $31 \%$ informam não receber qualquer valor como bônus devido à origem orgânica dos produtos. Os produtores que nada recebem de bonificação são produtores que vendem de porta em porta, em mercados ou supermercados, no atacado e na feira orgânica, que mesmo sendo uma feira de produtos orgânicos, segundo os produtores, opera com preços de mercado. Já os produtores que recebem a bonificação de $30 \%$, são aqueles que vendem aos programas governamentais, que tem tabelada a bonificação nesse percentual.

Em relação às transações, temos que: T1 (Insumos-Produtor): caracteriza-se como uma relação de mercado spot, com baixa especificidade; T2 (Produtor-Atacado): pouco frequente, baixa incerteza, baixa assimetria de informações e vendas predominantemente a vista; T3 (Produtor-Varejo): pouco frequente, baixa incerteza, baixa assimetria de informações e vendas predominantemente a vista; T4 (Produtor-Consumidor final): é mais frequente que as transações T2 e T3. Compreende a venda no local da produção e a venda de porta em porta. É baixa a incerteza, baixa assimetria de informações e vendas predominantemente a vista; T5 (ProdutorProgramas governamentais): é a mais frequente de todas as transações. Justifica essa predileção o fato de ser uma venda garantida, assim como o recebimento. Embora não seja uma venda a vista, os produtores dizem que não têm dificuldades de recebimento, sendo que entre 20 e 40 dias após a entrega há o depósito na conta do produtor. Ressalta-se que muitos produtores produzem exclusivamente para venda para os programas governamentais, o que caracterizaria a especificidade como 'dedicada'.

\section{CONCLUSÕES}

O projeto PAIS de Campo Grande representa um sistema coordenado para a produção sustentável de hortaliças orgânicas. Este sistema envolve um conjunto de transação entre produtores e atacado, produtores e varejo e produtores e consumidores finais. Essas transações são em sua maioria conduzidas por meio de relações de mercado, com exceção das vendas aos Programas de Governo (PAA e PNAE) que envolvem projeto, aqui entendido como contratos, com especificações de quantidade, prazo e garantia de preços. O projeto tem relevância, sobretudo, por ser uma iniciativa de coordenação de agricultores de baixa renda com foco na 
sustentabilidade. Sendo composto por agricultores familiares, a questão social assume destaque, sendo que a maioria dos produtores está satisfeita, sobretudo em relação aos ganhos em saúde e garantia de venda da produção, o que garante uma receita mínima para o sustento das famílias.

Para a operacionalização do projeto PAIS conta-se com o apoio de um conjunto de organizações como o SEBRAE (MS), Fundação Banco do Brasil, Prefeituras, Governo Federal (Ministérios de Integração Nacional e do Desenvolvimento Social) e uma Cooperativa (Organocoop).

O Sebrae (MS) tem o papel fundamental de fomentar a utilização da tecnologia e prover treinamentos de ordem operacional e gerencial. Após a seleção dos produtores, realizada pela prefeitura, o SEBRAE promove treinamentos e a entrega dos kits de materiais. Constata-se que o Estado, seja sob a figura da Prefeitura Municipal de Campo Grande, da instituição financeira ou dos Ministérios, exerce diferentes papéis desde atividades de fomento, assessoria técnica, concessão de crédito até a atuação como agente de comercialização, efetivamente adquirindo produtos por meio de Programas Governamentais. Este papel multifacetado do Estado que por um lado garante a continuidade do projeto, por outro representa um conjunto de vulnerabilidades, características de um sistema induzido.

Sendo um sistema concebido a partir de um modelo que deu certo em determinada localidade do Brasil, no caso, Petrópolis (RJ), o projeto PAIS demanda algumas adequações para a sua efetiva sustentabilidade no que tange à sua sobrevivência no longo prazo. Entre outras, cumpre ressaltar o necessário aprimoramento no processo de identificação e seleção de potenciais produtores a serem inseridos no projeto. No sistema, a prefeitura seleciona os produtores e depois os acompanha com assistência técnica. Nesse sentido, não há maior rigor nos pré-requisitos do processo seletivo. Em linhas gerais, é preciso ser agricultor familiar e querer integrar o projeto, com vistas à produção orgânica. Com isso, há produtores nas diversas localidades do município, desde a área urbana até assentamentos com mais de $100 \mathrm{~km}$ da cidade, além de diferenças nos tipos de solo, tamanho de propriedades, diversos tipos de produtos rurais, entre outras características gerais. Essas questões ressaltam os quão heterogêneos são os produtores. Esta heterogeneidade, que por um lado permite acesso a vários tipos de produtores, dificulta a coordenação do Projeto e a sua efetividade.

Porém, vale ressaltar que há limitações quanto ao número de produtores que podem ser escolhidos, principalmente pela questão financeira do projeto, que precisa dispor dos equipamentos/insumos para distribuição aos iniciantes, assim como são necessários os treinamentos. Ressalta-se também que a maior parte dos produtores foi selecionada nos primeiros anos da implantação do projeto. Não obstante a alta heterogeneidade do grupo de produtores, sobretudo quanto à localização das propriedades, o projeto conta com diversos agentes de fomento, cada qual com uma função específica no âmbito do seu fomento e execução esta diversidade (produtores e organizações de apoio) confere maior complexidade para o gerenciamento e monitoramento do projeto. 
Contando com diversos agentes de apoio, muitos dos quais não se relacionam diretamente, tem-se um ponto crítico do projeto. Exemplo disso é o PAA, que tem dois gestores, o município e a CONAB. Para o produtor isso é benéfico, pois em cada um destes projetos ele tem uma cota, mas para a coordenação do sistema é uma desvantagem, já que cada organização tem sua forma de trabalhar. Um resultado que evidencia a dificuldade de alcance dos objetivos do projeto PAIS é a renda média dos produtores, caracterizada como de baixa renda. Esse é um fator preocupante, pois demonstra que ainda são necessárias medidas para que se obtenha a sustentabilidade econômica almejada pelo projeto.

Embora a maioria dos respondentes indique estar satisfeita com os resultados, percebe-se que mesmo aqueles que tiveram melhoria na renda, esta melhoria não foi significativa. A satisfação quanto ao aspecto econômico pode ser mais relacionada à garantia de venda, pelo menos até os limites dos programas governamentais, do que aos ganhos, já que é melhor para o produtor ter para onde vender, que ter de sair "de porta em porta". Também a melhoria quanto à saúde merece destaque, pois é evidente o benefício da produção orgânica para a saúde dos trabalhadores e consumidores em se comparado com o modo convencional.

Como característica negativa, ressalta-se a grande dependência do projeto em relação aos programas governamentais quanto à comercialização da produção. Nesse sentido, cumpre destacar que os programas governamentais não são exclusivos de produtores do projeto PAIS; sendo destinados a agricultores familiares em geral. $O$ que diferencia produtores do projeto em relação aos demais produtores, são os dias diferenciados para entrega da produção (isso se a produção for orgânica) e também um adicional de 30\% sobre o valor de mercado (tabelado) para os produtos orgânicos. Assim, ações voltadas para a redução dessa dependência em relação aos Programas Governamentais fazem-se necessárias. Entende-se que o fortalecimento do papel da cooperativa seria uma solução para a identificação de canais alternativos para o escoamento da produção com foco no desenvolvimento de estratégias de agregação de valor ao produto (desenvolvimento de marcas, por exemplo)

No entanto, em relação à organização dos produtores, embora se tenha um número razoável de cooperados, não ficam evidentes os preceitos da cooperação entre eles. Ao que transmite, a maioria é cooperada devido aos benefícios oferecidos pela cooperativa como acesso a um canal exclusivo de distribuição (feira de orgânicos), e o transporte das mercadorias, que embora não alcance todos os cooperados, é muito valorizada por aqueles que recebem o benefício. Inclusive, alguns produtores afirmam que se houver a cessação da coleta por meio do caminhão da cooperativa, não haverá interesse em continuar com a produção, devido ao alto custo que teria com frete.

Assim, devido ao número e à heterogeneidade dos produtores, assim como das organizações de apoio, o projeto não atende todos os produtores da forma como estes gostariam. A prova disso é o elevado índice de desistência, que, se mantiverem as condições atuais, tende a aumentar. Nesse sentido, resta claro que um projeto como este, ou outro similar, deve considerar 
as especificidades de cada localidade para ter maior probabilidade de sucesso, pois um mesmo modelo não atende às necessidades e particularidades das diversas regiões do país.

Por fim, cabe destacar que se trata de um projeto inovador e ambicioso no sentido que busca prover soluções à agricultura familiar por meio da sua inserção em sistemas produtivos sustentáveis. Neste sentido, o apoio de parceiros é fundamental e o esforço de coordenação destes agentes é salutar, pois as organizações de apoio são determinantes para o sucesso do Programa, porém a complexidade da coordenação de suas atividades representa um desafio a ser ainda vencido.

\section{REFERÊNCIAS}

AZEVEDO, P. F.. A Nova Economia Institucional. São Paulo: Singular, 1997.

AZEVEdO, P. F.. Comercialização de Produtos Agroindustriais. São Paulo: Atlas, 2009.

CALEMAN, S. M. Q.. Coordenação do sistema agroindustrial da carne bovina: uma abordagem focada na teoria dos custos de mensuração. Dissertação (Mestrado em Agronegócios) - Universidade Federal de Mato Grosso do Sul, Campo Grande, 2005.

FARINA, E. M. M. Q.. Competitividade e coordenação de sistemas agroindustriais: um ensaio conceitual. Gestão \& Produção. v.6, n.3, p.147-161, 1999.

FERNANDES, C. M.. Avaliação do potencial de cooperação entre produtores do projeto de produção agroecológica integrada e sustentável - PAIS, no Mato Grosso do Sul. Dissertação (Mestrado em Desenvolvimento Local) - Universidade Católica Dom Bosco, Campo Grande, 2011.

FURUBOTN, E. G.; RICHTER, R.. Institutions and economic theory: the contribution of the new institutional economics. Ann Arbor: The University of Michigan Press, 2000.

MÉNARD, C.. The economics of hybrid organizations. International Journal of institutional and theoretical economics. v.160, n.3, p.345-376, 2004.

NORTH, D. C.. Institutions. The Journal of Economic Perspectives. v.5, n.1, p.97-112, 1991.

NORTH, D. C.. Custos de transação, instituições e desempenho econômico. 3 ed. Rio de Janeiro: Instituto Liberal, 2006.

RESENDE, C. L.; FARINA, E. M. M. Q.. Assimetria informacional no caso de alimentos orgânicos. In: SEMINÁRIO BRASILEIRO DA NOVA ECONOMIA INSTITUCIONAL, 2. Anais. São Paulo, 2001.

SEBRAE. PAIS - Produção Agroecológica Integrada e Sustentável: mais alimento, trabalho e renda no campo. Cartilha passo-a-passo. 3 ed. Brasília: SEBRAE, 2009.

VERGARA, S. C.. Projetos e relatórios de pesquisa em administração. 10 ed. São Paulo: Atlas, 2009.

WILLIAMSON, O. E.. The Economics Institutions of capitalism: firms, markets, relational contracting. New York: The Free Press, 1985.

WILLIAMSON, O. E.. Comparative economic organization: the analysis of discrete structural alternatives. Administrative Science Quarterly, v.36, n.2, p. 269-296, 1991.

WILLIAMSON, O. E.. The mechanisms of governance. New York: Oxford University Press, 1996.

WILLIAMSON, O. E.. The new institutional economics: taking stock, looking ahead. Journal of Economic Literature, v.38, p.595-613, 2000. 
ZYLBERSZTAJN, D.. Estruturas de governança e coordenação do agribusiness: uma aplicação da nova economia das instituições. Tese (Doutorado) - Universidade de São Paulo, São Paulo, 1995.

ZYLBERSZTAJN, D.. Economia das Organizações. São Paulo: Pioneira Thomson Learning, 2005. 